\title{
The Role of Nitric Oxide in Cancer Cell DNA Repair, Hypoxia Adaptation and Drug Resistance
}

\author{
Lizhi Liu and Weiming $\mathrm{Xu}$ * \\ The Krebs Institute, Department of Molecular Biology and Biotechnology, The University of Sheffield, S10 2TN, UK
}

\begin{abstract}
Nitric oxide (NO) has been widely characterized as an important signalling molecule in many biological systems. To study the role of $\mathrm{NO}$ in human breast cancer cells, we have developed tetracycline-inducible breast cancer cell MCF7 and co-culture systems in the breast cancer ZR75 cells. We have applied a functional genomic approach using micro arrays and antibody-based proteomic methods to study effects of $\mathrm{NO}$ in these cells. We found that many DNA-repair genes appear up-regulated including DNA-Pkcs, topoisomerase 2, and Rad 2. Some oncogenes and tumour suppressor genes also appear up regulated, such as Ret/Ptc2 and c-Yes-1. In accompanied with respiration inhibition, some of the hypoxia regulated genes; such HIF- $\alpha$ and GRP78 are also up-regulated. These different targets could contribute different effects in cancer cell DNA repair, hypoxia adaptation and drug resistance, leading us to develop the therapeutic intervention against cancer.
\end{abstract}

Keywords: Nitric oxide; cancer; DNA-PK; topoisomerase, rad 2; ret; c-yes-1; GRP78; MCF7; ZR75

\section{Introduction}

Nitric oxide (NO) has been widely characterized as an important signalling molecule in many biological systems [1]. NO is generated by a family of NO synthases (NOSs), of which there are three isoforms endothelial (eNOS), neuronal (nNOS) and immunologically induced (iNOS). Various studies have shown that all three isoforms may be involved in promoting or inhibiting the aetiology of human cancer $[2,3]$. NO (and related reactive nitrogen species) may have both genotoxic and angiogenic properties. Increased NO generation in a cell may select mutant p53 cells and contribute to tumour angiogenesis by up-regulating VEGF and regulation of HIF-1a [4-7]. In addition, NO may modulate tumour DNA repair mechanisms by up-regulating p53, poly (ADP-ribose) polymerase (PARP) and the DNA-dependent protein kinase (DNA-PK) [7,8].

We were the first group to show that the expression of iNOS could lead to multiple-drug resistance in cancer cells $[7,8]$. The notion is supported by recent findings showing that depleting endogenous NO enhances cisplatin-induced apoptosis in melanoma cells [9]. Furthermore, iNOS expression in B-cell chronic lymphocytic leukaemia may confer apoptosis resistance by up-regulating DNAPK activity [10]. However, high concentrations of NO may have the opposite effect. Adenoviral gene transfer of the iNOS gene enhances the radiation-response of human colorectal cancer treatment [11]. In fact, over the last decade, many reports have presented both positive and negative aspects of NO in tumour biology. Some reports found NO to be either cytostatic or cytotoxic [12]. For example some studies show that NO provides cytoprotection to tumour cells by increasing their angiogenic activity and hypoxia adaptation [13]. For instance, the key angiogenic factor, VEGF, has been found to be either up-regulated [14] or down-regulated by NO [15]. Jenkins et al [13] found that an iNOS cDNA expression cassette transfected into human colon cancer DLD-1 cells (which generate $20 \mathrm{pmol} / \mathrm{min} / \mathrm{mg}$ NOS activity) promoted tumour growth [13]. However in DLD-1/recombinant iNOS-inducible cell culture, which generating $300 \mathrm{pmol} / \mathrm{min} / \mathrm{mg}$ NOS activity showed a reduction in tumour growth [16] (Figure 1). We have proposed that there is a dose-dependent effect of NO on tumour growth [2]. In general, high levels of iNOS expression may be cytostatic or cytotoxic for tumour cells, whereas lower activity can have the opposite effect and promote tumour growth. Because of the complexity of NO reaction(s) in cancer, the traditional NOS inhibitors are difficulty to apply directly in cancer treatments. To study the role of NO in human breast cancer cells, we have developed tetracycline-inducible breast cancer cell MCF7 and co-culture systems in ZR75 cells. We have applied a functional

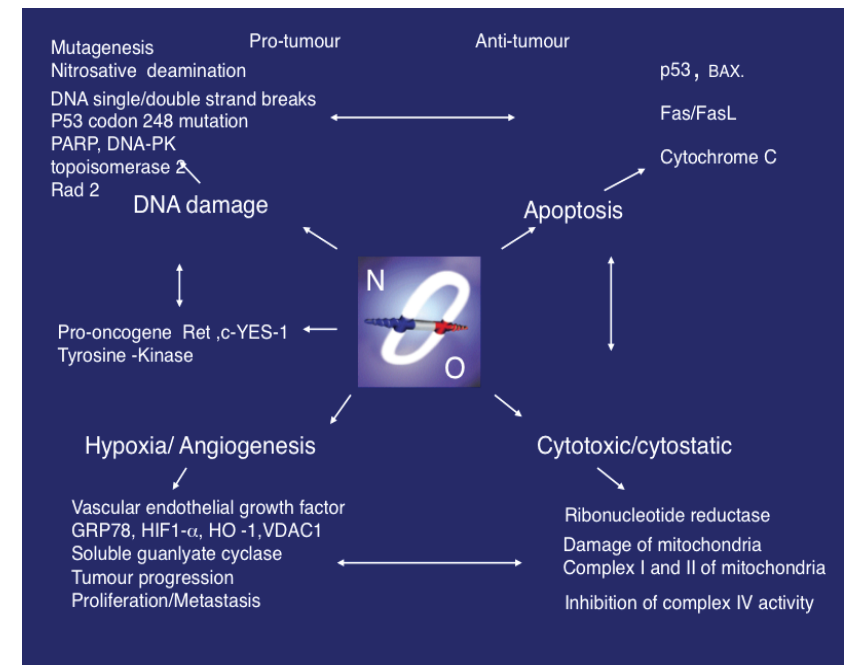

Figure 1: A schematic representation of the dual action of nitric oxide in tumour growth.

*Corresponding author: Weiming $\mathrm{Xu}$, The Krebs Institute, Department of Molecular Biology and Biotechnology, The University of Sheffield, S10 2TN, UK, E-mail: weimingx.xu@gmail.com, Weiming.xu@sheffield.ac.uk

Received August 20, 2012; Accepted December 14, 2012; Published December 17, 2012

Citation: Liu L, Xu W (2013) The Role of Nitric Oxide in Cancer Cell DNA Repair Hypoxia Adaptation and Drug Resistance. Single Cell Biol 2: 103. doi:10.4172/21689431.1000103

Copyright: () 2013 Liu L, et al. This is an open-access article distributed under the terms of the Creative Commons Attribution License, which permits unrestricted use, distribution, and reproduction in any medium, provided the original author and source are credited. 
Citation: Liu L, Xu W (2013) The Role of Nitric Oxide in Cancer Cell DNA Repair, Hypoxia Adaptation and Drug Resistance. Single Cell Biol 2: 103. doi:10.4172/2168-9431.1000103

Page 2 of 5

genomic approach using micro arrays and antibody-based proteomic methods to study dose-dependent effects of NO in these cells.

\section{Materials and Methods}

Cell culture: MCF-7 and ZR75 cells were obtained from European collection of cell culture (Wiltshire, UK). The tetracyline-inducible cell line- Tex293 clone 22 carrying transfected human iNOS cDNA under the control of a tetracycline-inducible promoter was prepared as described previously [16]. Cell were grown in DMEM containing $25 \mathrm{mM}$ glucose and $10 \%$ fetal calf serum, as described [17].

\section{DNA transfection and generation of tetracycline-inducible MCF7 cell line}

The tetracycline-regulated mammalian expression vector pcDNA4/TO (Invitrogen, Carlsbad, CA) was used to generate a human iNOS cDNA expression construct. To develop tetracycline-inducible NO-generating cell lines, the pcDNA4/TO-iNOS and pcDNA6/TR (Invitrogen) constructs were co-transfected into MCF7 cells and dual selection using Zeocin for the human iNOS gene and blasticidin for the Tet repressor gene was carried out. A panel of 25 cell lines was isolated

A
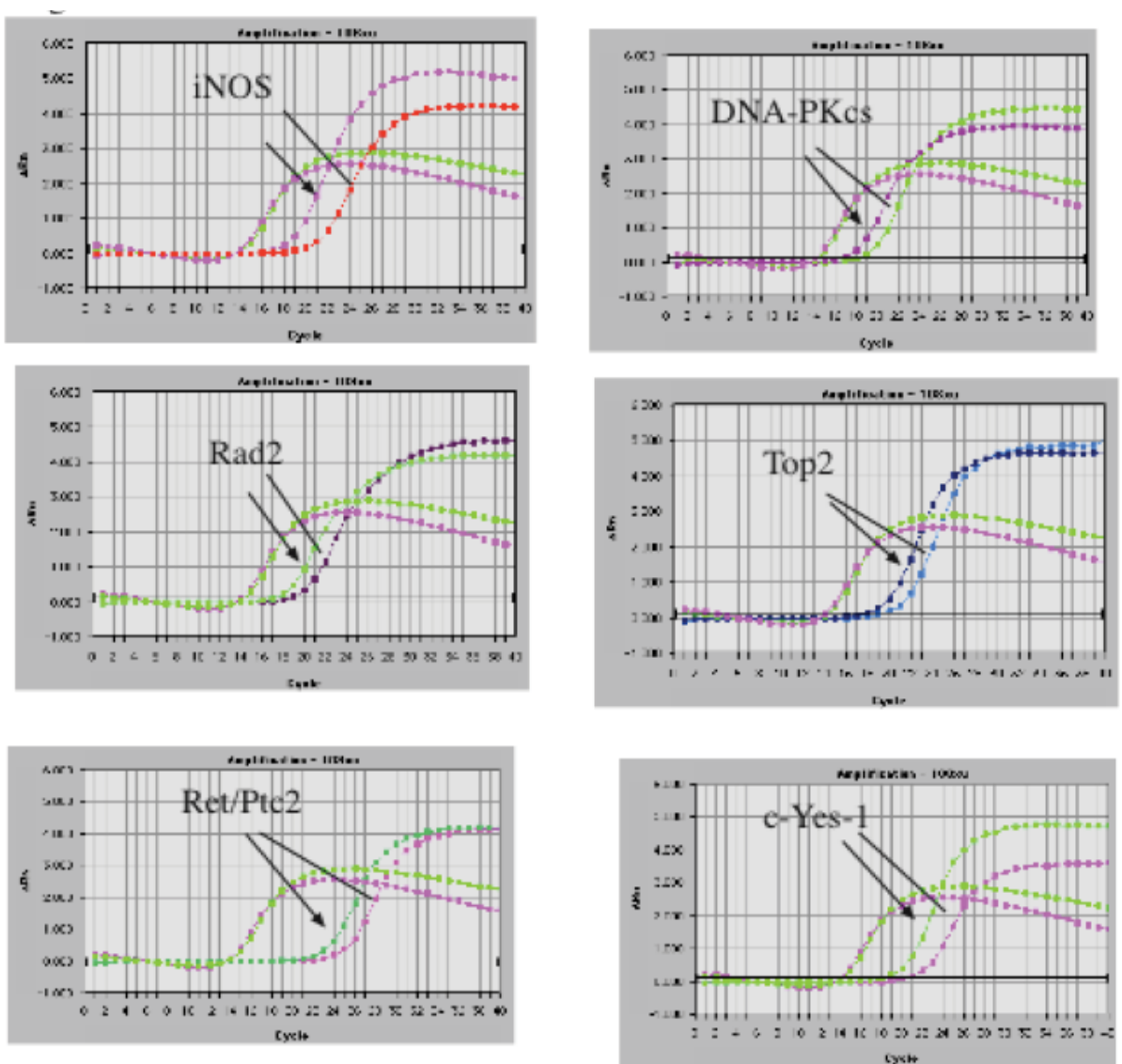

B

UV resistance in MCF-7 Tet on clone-5

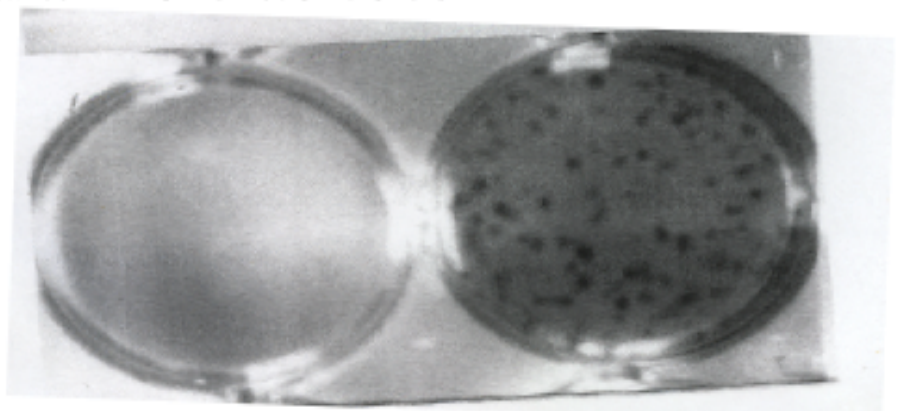

Uninduced

Tc-induced, NO generating cells

Figure 2: MCF-7 tet-on clone 5. A. Real-time RT PCR assay detecting iNOS, DNA-Pkcs, topoisomerase 2 (Top2) Rad 2, Ret and c-Yes-1 transcripts. All six genes are significantly up-regulated after induction $\left(10 \mathrm{ng} / \mathrm{ml}\right.$ tetracycline) for $16 \mathrm{~h}$. B. Following exposure of cells to $120 \mathrm{~mJ} / \mathrm{cm}^{2} \mathrm{UV}-\mathrm{C} . \mathrm{m}^{2}$, the tetracycline-induced cells showed significant UV-c resistance with 10-fold more colonies surviving (stained with methyl green) than untreated cells after two weeks growth. 
Citation: Liu L, Xu W (2013) The Role of Nitric Oxide in Cancer Cell DNA Repair, Hypoxia Adaptation and Drug Resistance. Single Cell Biol 2: 103. doi:10.4172/2168-9431.1000103

A

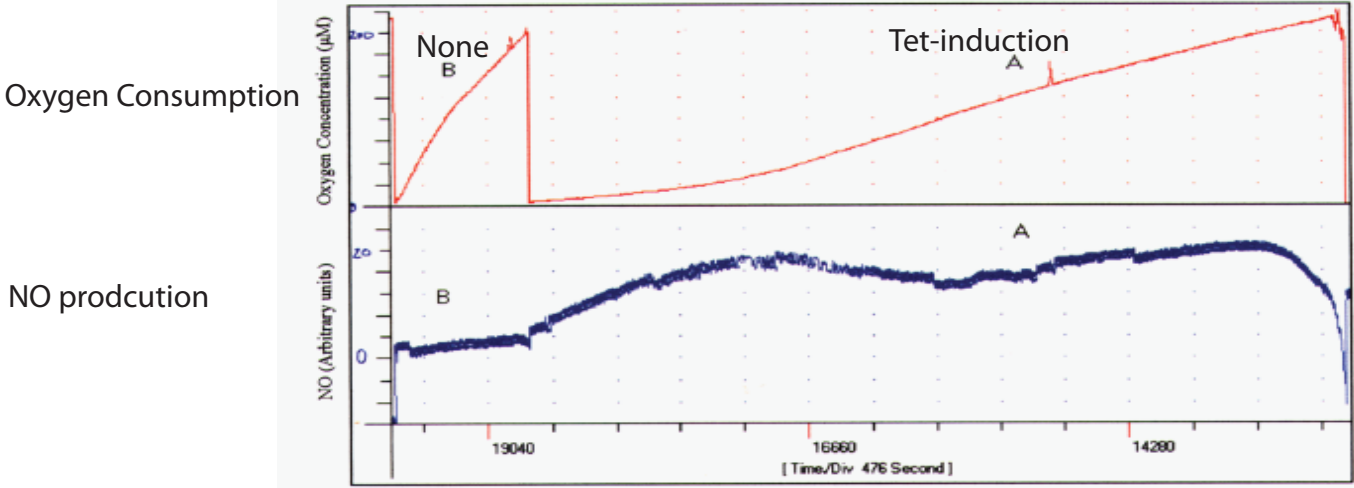

B
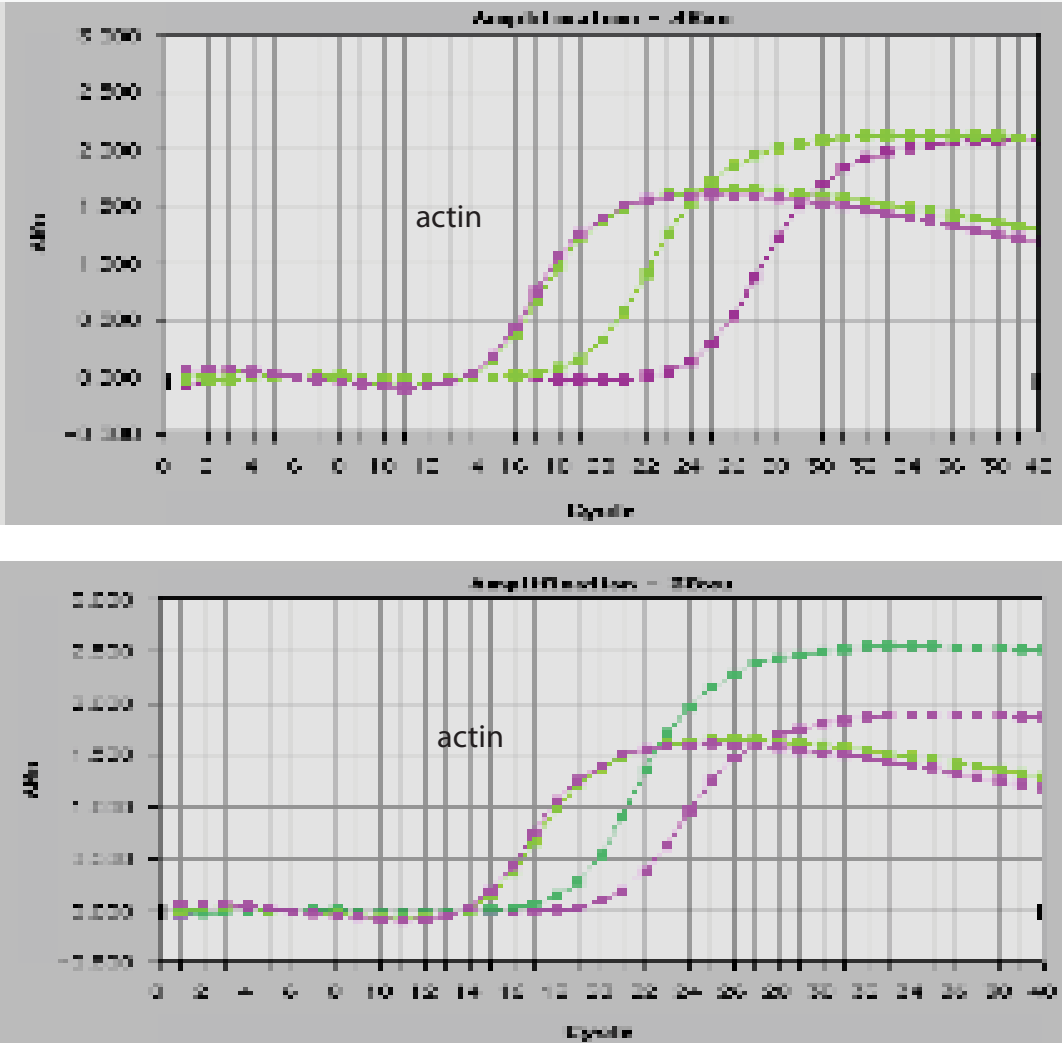

GRP78

Hif-1

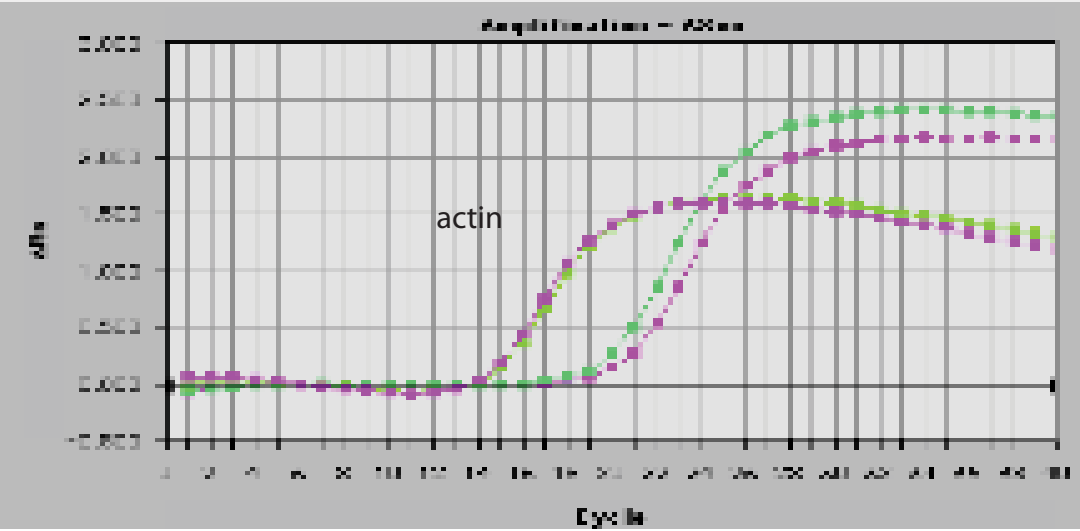

Figure 3: NO causes inhibition of respiration and alterations in patterns of gene expressing in a co-culture model using ZR75-1 breast cancer cells grown alongside NO-generating cells. A. Respiration rate is reduced significantly as NO concentration increases. B. Confirmation of the microarray data by real-time PCR for iNOS, Hinf-1a and Grp78 mRNA. Green lines indicate the NO-induced samples; Purple solid lines indicate the un-induced samples. Actin was used as a control, (show as the traces on the left of the graphs). 
showing tetracycline-dependent $(10 \mathrm{ng} / \mathrm{ml})$ induction of NO. MCF7-5 was selected for further study.

\section{Nitrite assay, nitric oxide and oxygen consumption measurement}

Griess reaction (Promega, UK) which contains 1\% sulfanilamide, 0.1\% n-1-naphthylene diamine Dihydrochloride, was used to measure the nitrite concentration in the medium, which is used as a reflection of NO production. Absorbance at $540 \mathrm{~nm}$ against a reference $620 \mathrm{~nm}$ was measured with sodium nitrite as a standard. Nitric oxide and oxygen consumption measurements were carried out as described [17]

\section{Breast cancer cell and NO-producing cell co-culture}

To study the NO-mediated tumor cell-killing, we co-cultured human breast cancer cell line, ZR75-1with No-generating Tex293 clone 22 cells. We mixed together $10^{6}$ DLD- 1 cells and $2 \times 10^{6}$ Tex 293 clone 22 cells and seeded them overnight into 6-well plates.

\section{RNA isolation, Microarrays and Real time RT-PCR analysis}

Total RNAs were extracted from the NO-generating cells and control cells using Trizol reagent (Invitrogen, UK). Polyadenylated (poly $\mathrm{A}^{+}$) RNA will be purified from total RNA and synthesis of cDNA involved use of T7-(dT)24 primers and SuperScript II according to manufacturer's instructions (Invitrogen, UK). In vitro transcription was performed to produce biotin labeled cRNA using a bioarray high yield RNA transcription labeling kit (Enzo Diagnostics, USA). cRNA was fragmented to about $200 \mathrm{bp}$ (Affymetrix, USA) and hybridized with the HG-U95Av2 array represents approximately 10,000 fulllength genes. The resulting expression data were analyzed by MAS 5.0 (Affymetrix) software for the data normalization, data clustering, expression profiling. The microarray results will be further confirmed by the Taq Man real time RT-PCR method. The relative amounts of all mRNAs were calculated using the relative cycle threshold method (Perkin-Elmer, Norwalk, CT).

\section{Results and Discussion}

\section{Generation of the tetracycline-inducible NO-producing MCF7 cell line}

We have carried out transfection experiment using our tetracycline constructs and successful isolated a panel of tetracycline-inducible NO-producing MCF7 cell lines. One of the clones, MCF7 Tet-on clone 5 , can generate up to $20 \pm 5 \mu \mathrm{M}$ nitrite $/ 10^{6}$ cells $(\mathrm{n}=3)$ by $10 \mathrm{ng} / \mathrm{ml}$ tetracycline in $24 \mathrm{~h}$. This induction can be completely inhibited by addition of the NOS inhibitor L-NIO $(20 \mu \mathrm{M})$.

\section{Gene Array Analysis of NO-producing MCF7 Tet-on clone 5 cell}

We have also carried out Affrymetrix array analysis (U95 Av2) on the MCF7 Tet-on clone 5 and found that over 100 genes are upregulated and 50 are down-regulated over $2 \pm 0.5$-fold gene expressing changes (Xu et al. unpublished data) using the 12,000-gene array format (using $10 \mathrm{ng} / \mathrm{ml}$ tetracycline induction). Many of the genes can be clustered into families, such as DNA-repair gene family including DNA-Pkcs, topoisomerase 2, and Rad 2. Some oncogenes and tumour suppressor genes appear regulated, such as Ret/Ptc2 and c-Yes-1. Interestingly, both of these genes are tyrosine kinases and are significantly up-regulated (over 3 fold). We have used real-time PCR to confirm some of the array data (Figure 2A).

\section{NO-producing breast cancer cells are UV resistance}

We have also carried out cytoprotection assays using $120 \mathrm{~mJ} / \mathrm{cm}^{2}$ UV-C to examine the MCF7 Tet-on clone 5 UV resistance. As shown on figure $1 \mathrm{~b}$, the tetracycline induced cells in MCF-7 tet-on clone 5 showed significant UV-C resistance after tetracycline induction (10 ng/ $\mathrm{ml}$ ), with 10 -fold more colonies (stained with methyl green) surviving in NO-treated cells compared with untreated cells (Figure 2B).

\section{NO regulates hypoxia regulated genes in breast cancer cell and NO-producing cell co-culture}

Using NO-generating cells and breast cancer cell lines ZR75 coculture system, we found that there were several hypoxia regulated genes, e.g. HIF1- $\alpha$ and GRP78 (Figure 3B) were up-regulated accompanied by nitric oxide increase and respiration rate decrease (Figure 3A).

Cancer had become one of the leading causes of death in the developed world. Multi-drug resistance and angiogenesis-related metastasis are the major problems facing cancer patients. We have shown here that a free radical gas, nitric oxide $(\mathrm{NO})$ contributes to cancer cell DNA repair, hypoxia adaptation, drug resistance and apoptosis. Recently, our studies on NO-mediated cytoprotection showed an NOmediated increase in expression of a hypoxia-regulated gene, glucose regulated protein 78 (Grp78) [17]. We have isolated specific antiGRP78 scFV antibody [18] and conjugated it with quantum-dot and shows the conjugated scFV GRP78 antibody processes the antitumor activity in vivo and in vitro [19]. The antibody-mediated tumour killing with Fas:Fc antibody has previously successfully used to target cancer cell apoptosis [16]. Here we report developing further NO-inducible system in breast cancer cells. We found that hypoxia regulated gene HIF- $\alpha$ $\varepsilon v \varepsilon$ expression was up-regulated (Figure 3B). We have also discovered several novel targets, which are NO-regulated, such as topoisomerase 2(TOP2), and Rad 2 genes (Figure 2A). TOP2 gene amplifications or deletions have been found to associated with an increase in responsiveness to anthracycline-containing chemotherapy regimens relative to non-anthracycline regimens that is similar to that seen in patients with HER2 amplification [20]. Rad 2 gene is a singlestranded DNA endonuclease [21] being involved in excision repair of DNA damaged with UV light, bulky adducts, or cross-linking agents. Increasing its expression could lead UV-C resistance observed in NOproducing breast cancer cells (Figure 2B). Some oncogenes and tumour suppressor genes also appear regulated, such as Ret/Ptc2 and c-Yes-1. Ret mutations are involved in the hereditary Medullary Thyroid Carcinoma (MTC) [22] and tyrosine kinase inhibitors targeting activated RET are currently in clinical trials for the treatment of patients with MTC. C-Yes-1 is a non-receptor protein tyrosine kinase, involved in binding to many receptor tyrosine kinases including EGRF, PDGFR, CSF1R and FGFR [23]. Interesting, the Ret and c-YES-1 are both tyrosine-kinases, rich drugable targets for developing small molecules for cancer treatment. The newly discovered nitric oxide targets described here will lead us to develop more therapeutic agents against cancer.

\section{References}

1. Li L, Huq S, Xu W (2009) Targeting Cyclooxygenase and Nitric Oxide Pathway Cross-Talk: A New Signal Transduction Pathway for Developing More Effective Anti-Inflammatory Drugs. Current Signal Transduction Therapy 4: 6675.

2. Xu W, Liu LZ, Loizidou M, Ahmed M, Charles IG (2002) The role of nitric oxide in cancer. Cell Res 12: 311-320.

3. Fukumura D, Kashiwagi S, Jain RK (2006) The role of nitric oxide in tumour progression. Nat Rev Cancer 6: 521-534. 
Citation: Liu L, Xu W (2013) The Role of Nitric Oxide in Cancer Cell DNA Repair, Hypoxia Adaptation and Drug Resistance. Single Cell Biol 2: 103. doi:10.4172/2168-9431.1000103

Page 5 of 5

4. Hofseth LJ, Saito S, Hussain SP, Espey MG, Miranda KM, et al. (2003) Nitric oxide-induced cellular stress and p53 activation in chronic inflammation. Proc Natl Acad Sci U S A 100: 143-148.

5. Kimura H, Esumi $H(2003)$ Reciprocal regulation between nitric oxide and vascular endothelial growth factor in angiogenesis. Acta Biochim Pol 50: 49-59.

6. Hagen T, Taylor CT, Lam F, Moncada S (2003) Redistribution of intracellular oxygen in hypoxia by nitric oxide: effect on HIF1alpha. Science 302: 19751978.

7. Naura AS, Datta R, Hans CP, Zerfaoui M, Rezk BM, et al. (2009) Reciprocal regulation of iNOS and PARP-1 during allergen-induced eosinophilia. Eur Respir J 33: 252-262.

8. Xu W, Liu L, Smith GC, Charles IG (2000) Nitric oxide upregulates expression of DNA-PKcs to protect cells from DNA-damaging anti-tumour agents. Nat Cell Biol 2: 339-345.

9. Tang $\mathrm{CH}$, Grimm EA (2004) Depletion of endogenous nitric oxide enhances cisplatin-induced apoptosis in a p53-dependent manner in melanoma cell lines. J Biol Chem 279: 288-298.

10. Guipaud O, Deriano L, Salin H, Vallat L, Sabatier L, et al. (2003) B-cell chronic lymphocytic leukaemia: a polymorphic family unified by genomic features. Lancet Oncol 4: 505-514.

11. Wang Z, Cook T, Alber S, Liu K, Kovesdi I, et al. (2004) Adenoviral gene transfer of the human inducible nitric oxide synthase gene enhances the radiation response of human colorectal cancer associated with alterations in tumor vascularity. Cancer Res 64: 1386-95.

12. Hibbs JB Jr, Taintor RR, Vavrin Z (1987) Macrophage cytotoxicity: role for L-arginine deiminase and imino nitrogen oxidation to nitrite. Science 235: 473 476

13. Jenkins DC, Charles IG, Thomsen LL, Moss DW, Holmes LS, et al. (1995) Roles of nitric oxide in tumor growth. Proc Natl Acad Sci U S A 92: 4392-4396.
14. Ambs S, Merriam WG, Ogunfusika MO, Bennett WP, Ishibe N, et al. (1998) p53 and vascular endothelial growth factor regulate tumor growth of NOS2expressing human carcinoma cells. Nat Med 4: 1371-1376.

15. Tsurumi Y, Murohara T, Krasinski K, Chen D, Witzenbichler B, et al. (1997) Reciprocal relation between VEGF and NO in the regulation of endothelia integrity. Nat Med 3: 879-886.

16. Xu W, Liu L, Charles IG (2002) Microencapsulated iNOS-expressing cells cause tumor suppression in mice. FASEB J 16: 213-215.

17. Xu W, Liu L, Charles IG, Moncada S (2004) Nitric oxide induces coupling of mitochondrial signalling with the endoplasmic reticulum stress response. Nat Cell Biol 6: 1129-1134

18. Liu L, Xu W (2009) Targeting Nitric Oxide Mediated Upregulation of Membranebound Glucose Regulated-protein 78 by Subtractive Single Chain Variable Fragment (scFv) Phage Display. American Journal of Biomedical Sciences 1 : 321-335.

19. Xu W, Liu L, Brown NJ, Christian S, Hornby D (2012) Quantum dot-conjugated anti-GRP78 scFv inhibits cancer growth in mice. Molecules 17: 796-808.

20. O'Malley FP, Chia S, Tu D, Shepherd LE, Levine MN, et al.(2009) Topoisomerase II alpha and responsiveness of breast cancer to adjuvant chemotherapy. J Natl Cancer Inst 101: 644-650.

21. Habraken Y, Sung P, Prakash L, Prakash S (1993) Yeast excision repair gene RAD2 encodes a single-stranded DNA endonuclease. Nature 366: 365-368.

22. Lodish MB, Stratakis CA (2008) RET oncogene in MEN2, MEN2B, MTC and other forms of thyroid cancer. Expert Rev Anticancer Ther 8: 625-632.

23. Sato I, Obata Y, Kasahara K, Nakayama Y, Fukumoto Y, et al. (2009) Differentia trafficking of Src, Lyn, Yes and Fyn is specified by the state of palmitoylation in the SH4 domain. J Cell Sci 122: 965-975. 